\title{
Data Envelopment Analysis Application in Turkish Energy Market
}

\author{
Özlem Coşgun ${ }^{\dagger}$ \\ Fatih University, Department of Industrial Engineering, \\ Istanbul, 34500, Turkey \\ Gamze Ogcu Kaya \\ Fatih University, Department of Industrial Engineering, \\ Istanbul, 34500,Turkey \\ E-mail: gamzeogcu@st.fatih.edu.tr \\ www.fatih.edu.tr
}

Received 6 September 2013

Accepted 1 June 2014

\begin{abstract}
In this study, we consider data envelopment analysis for comparison between thermal energy plants which are natural gas based and coal based power plants. Results of this study will give a roadmap to decision makers in selecting type of thermal plant they will construct. Also public and private energy supply sources are compared based on their performances. We not only make a solely comparison but also make a ranking of the power plants considered by using goal programming technique.
\end{abstract}

Keywords: Data Envelopment Analysis, Goal Programming, Energy, Power Plants

\section{Introduction}

Highly growing Turkish Economy in the last decade leads to substantial increase in energy consumption. In order to respond to this increase in demand, new power plants are being constructed by both private and public enterprises at the supply side. This situation resulted in decision makers who are constructing new power plants to face with a crucial decision on which energy source to invest.

Efficiencies of power plants in Turkey are investigated and compared in this study. Turkey is a fast developing country whose electric power supply and demand have shown rapid increases in the last decade and this trend is expected to continue in the future. Accordingly, new power plant investment decision and operation of existing power plants is a crucial issue. In this regard, type of source, efficiency and ownership of power plants are key characteristics to be investigated, in answering the question "Which one is better with respect to others and why?". Many studies involving comparisons among types of power plants have been made in order to obtain the best answer to this question ${ }^{1}$.

This study involves a multi-input-multi-output performance evaluation and comparison of a set of power plants in Turkey based on real data. We analyse and compare efficiencies of public versus private power plants and coal based power plants versus natural gas based power plants. This issue is handled within the framework of an appropriate mathematical tool, named data envelopment analysis (DEA), which was introduced by Charnes, Cooper and Rhodes ${ }^{2}$.

DEA (Data envelopment analysis) is an efficient tool for evaluating relative efficiency of entities which are called as DMU (Decision making unit). It is a widely used technique that can be applied to decision making units of any kind, DMUs can be selected from production sector and service sector. DEA can be applied to evaluate efficiencies of homogenous multiple input and output organizations, such as bank branches, schools, airports, tax offices, and hospitals ${ }^{3,4}$. Efficiency score of a DMU can be between 0 and 1 or can be expressed as $0 \%$ and $100 \%$. The efficiency score 1 or $100 \%$ of a decision making unit (DMU) point out that DMU is relatively efficient to other units in the data sample.

There are plenty of studies on DEA applications in health sector ${ }^{5,6,7,8}$. Since DEA methodology has a widespread application area, it is also used in farming $9,10,11,12$. DEA can also be used as a benchmarking tool that recognizes inefficient DMUs by comparing them with similar DMUs

\footnotetext{
${ }^{\dagger}$ Özlem Coşgun, ozlem_ince@hotmail.com, Fatih University, Department of Industrial Engineering, Istanbul, 34500 Turkey 
considered as efficient. In contrast with other benchmarking methods that depend mostly on the view of managers, DEA is capable of establishing best examples that are very hard to be precisely found by remarkably ${ }^{13}$. DEA has received significant attention in recent years due to its advantages over traditional methods for performance evaluation purposes ${ }^{14,15,16,17,18}$. DEA has also many applications on energy sector. Onut and Soner generated a DEA model for the evaluation of energy use and efficiencies of medium sized enterprises in Turkey ${ }^{19}$. Energy cost is included in the operational costs of a company and a decrease of it will add to the profitability of the company. In order to obtain energy efficiency, a company can either use less energy or increase rate of production. For enterprises, energy efficiency objective can be maintained by using higher efficiency equipments, improving energy use in operation and maintenance practices during production or using systems for monitoring or controlling energy use. For the DEA model used in the study, annual total sales and annual total profit are outputs where annual electricity consumption, annual natural gas consumption, annual oil consumption and annual LPG consumption are taken as inputs.

Martínez considered energy efficiency performances of non-energy intensive sectors in Germany and Colombia ${ }^{20}$. Authors investigated energy efficiency development from 1998 to 2005. Olatubi, Dismukes studied cost efficiencies of coal fired power plants and pointed out effects of fuel type, technology, vintage and size on operating efficiency $^{21}$. Application of DEA on energy efficiency is not restricted to thermal energy sources; José Ramón San Cristóbal studied the efficiency of the renewable energy technologies ${ }^{22}$. Lee applied data envelopment analysis on the energy efficiency of government buildings by investigating environmental and management factors $^{23}$. Lee and Lee also considered building energy performance with the help of DEA methodology ${ }^{24}$.

Sadjadi and Omrani generated data envelopment analysis model for performance assessment of electricity distribution companies where there is uncertainty in parameters ${ }^{25}$. Erturk and Türüt Aşık analyzed the performance of natural gas distribution companies by using data envelopment analysis on Turkish natural gas distribution companies and revealed significant factors affecting efficiency ${ }^{26}$. Fallahi, Ebrahimi, Ghaderi used DEA for evaluating technical efficiencies in electric generation management companies ${ }^{27}$. Sözen, Alp and Kilinc considered efficiency evaluation of renewable energy power plants, particularly hydroelectric power plants in Turkey and used two efficiency indexes based on production and energy unit cost performance ${ }^{28}$. Another research on power plant efficiency by using DEA is the work by Liu, Lin and Lewis where the authors evaluated thermal power plant efficiencies ${ }^{29}$. Golany et al. also considered power plant efficiency by using DEA methodology where the authors selected installed capacity, fuel consumption, manpower as inputs and generated power, operational availability, deviation from operational parameters and $\mathrm{SO}_{2}$ emissions as output factors. These factors were selected from a bigger list after examining the correlation between factors and eliminating redundant ones. The authors emphasized air pollution in their model by using the factor $\mathrm{SO}_{2}$ emissions as the categorical variable which has three levels as good, medium and bad emissions ${ }^{33}$. Another study on application of DEA in power plant efficiency is the work by Chitkara in which coal based generating units belonging to National Thermal Power Corporation of India are analyzed. Generation per unit of coal consumed, generation per unit of oil consumed and generation per unit of auxiliary power consumption are used as performance indicators ${ }^{34}$. Behera and Dash also analyzed efficiency of coal-based power plants in India by using Data Envelopment Analysis and concluded that average technical efficiency of the plants was found to be $83.2 \%{ }^{35}$. DEA approach is also used by Sueyoshi and Goto for evaluating Japanese fossil fuel power generation. DEA approach proposed in the study includes the output separation as desirable and undesirable ones and also the input separation as energy and non-energy ones $^{36}$.

In this study, DEA methodology is used for evaluating performance of thermal power plants consisting of coal fired and natural gas fired power plants. For the analysis, 20 plants are selected half of which belong to private sector companies and the other half belong to public sector. Evaluation is done based on two perspectives which are operational and investment efficiencies for both public sector plants and private sector plants separately. Operational efficiency is for evaluating performance of a power plant from operational perspective which includes financial, environmental and productivity measures. On the other hand, investment efficiency is for evaluating performance of a power plant considering its investment phase which contains cost, time and capacity perspectives. Also an overall comparison is made for all power 
plants. Moreover, we also compare the efficiencies of natural gas based power plants and coal based power plants to give information about the type of thermal plant that will be constructed. The study is important for contributing energy sector by making DEA application which gives insights for the market players. Also as mentioned in the literature section, Sözen, Alp and Kilinc ${ }^{28}$ considered efficiency evaluation of renewable energy power plants in Turkey and Liu, Lin and Lewis ${ }^{29}$ evaluated thermal power plant efficiencies in Taiwan. So we make a study like a combination of these two studies. We studied power plant efficiencies in Turkey. In addition to evaluation of plants, the ranking between the plants is done by using Goal Programming since DEA doesn't provide ranking.

\section{DEA Methodology}

DEA is a (linear) programming based technique and the basic model only requires information on inputs and outputs. Method is a special linear programming model for evaluating comparative efficiency of multiple-input multiple-output decision making units (DMUs).

DEA uses mathematical programming methods, it focuses on individual observation and emphasize revealed best practice frontier. The strength of DEA comes from its ability to simultaneously utilize multiple outputs and multiple inputs with each being stated in different units of measurement. The technique also has no restriction on the functional form of the input-output relationship (Charnes et al., 1994). Performance of DMU is directly compared with the most efficient of a peer or a combination of the most efficient peers.

In this study, we used CCR model proposed by Charnes, Cooper and Rhodes (1978) ${ }^{30}$. CCR Model developed by the authors can be grouped into two as input oriented and output oriented models. Both input oriented and output oriented methods aim increasing efficiency of a DEA inefficient DMU and make it efficient. For increasing efficiency, an input oriented model provides information on the required proportional reduction of inputs while keeping the current level of output. On the contrary, an output oriented model provides information on how much increase of output is required but at the same time maintaining the current level of inputs.

Output oriented CCR model is used in this study since increase in outputs for both operational and investment efficiency evaluations are desired. General form of output oriented CCR model introduced by Charnes, Cooper and Rhodes (1978) is as follows:
$\operatorname{Min} Z_{0}=\sum_{i=1}^{n} a_{i_{0}} x_{i_{o}}$

Subject to;

$\sum_{j=1}^{m} b_{j_{0}} y_{j_{o}}=1$

$\sum_{i=1}^{n} a_{i_{0}} x_{i_{h}}-\sum_{j=1}^{m} b_{j_{0}} y_{j_{h}} \geq 0 \quad$ for $h=1,2, \ldots, k$

$a_{i_{0}}, b_{j_{0}} \geq 0$ for $i=1, \ldots, n$ and $j=1, \ldots, m$

where $Z_{0}$ is the efficiency score of $0_{\text {th }}$ organization, $x_{i_{h}}$ is the observed value of input $i$ for the organization $h, y_{j_{h}}$ is the observed value of output $j$ for the organization $h, a_{i 0}, b_{j_{0}}$ are the weights assigned to input $i$ and output $j$ of organization $0, k$ is the number of organizations, $m$ is the number of outputs and $n$ is the number of inputs.

\section{Goal Programming Model}

Goal Programming (GP) is an important technique for decision-makers (DMs) to consider simultaneously several objectives in finding a set of acceptable solutions. It can be said that GP has been, and still is, the most widely used technique for solving multi-criteria and multi-objective decision- making problems. The DMs for their goals set some acceptable aspiration levels, $g_{k}(k=1,2, \ldots, n)$, for these goals, and try to achieve a set of goals as closely as possible (Tamiz, et al., 1998) ${ }^{31}$. The purpose of GP is to minimize the deviations between the achievement of goals, $f_{k}(X)$, and these acceptable aspiration levels, $g_{k}(k=1,2, \ldots, n)$. A mathematical formulation of GP is given below.

(GP)

$$
\begin{aligned}
& \text { Minimize } \sum_{k=1}^{n}\left|f_{k}(X)-g_{k}\right| \\
& \text { subject to } X \in F, \quad(F \text { is a feasible set })
\end{aligned}
$$

where $f_{k}(X)$ is the linear function of the $k_{\text {th }}$ goal, and $g_{k}$ is the aspiration level of the $k_{\text {th }}$ goal. The majority of GP applications in the literature have been implemented using various methods such as lexicographic GP (preemptive GP), weighted GP (Archimedean GP), and MINMAX GP (Chebyshev GP) (Romero, 2001) $)^{32}$. In order to solve GP, we let the function $f_{k}(X)=d_{k}^{+}-d_{k}^{-}+g_{k}$, then GP can be formulated as the following achievement function. 


$$
\begin{array}{ll}
\operatorname{Minimize} & \sum_{k=1}^{n}\left(d_{k}^{+}+d_{k}^{-}\right) \\
\text {subject to } & f_{k}(X)-g_{k}=d_{k}^{+}-d_{k}^{-}, k=1,2, \ldots, n \\
& X \in F, \quad(F \text { is a feasible set }) \\
& d_{k}^{+}, d_{k}^{-} \geq 0, \quad k=1,2, \ldots, n
\end{array}
$$

where $\quad d_{k}^{+}=\max \left(0, f_{k}(X)-g_{k}\right) \quad$ and $d_{k}^{-}=\max \left(0, g_{k}-f_{k}(X)\right) \quad$ are, respectively, overand under-achievement of the $k_{\text {th }}$ goal; other variables are defined as in GP. We use goal programming to make a ranking for efficient power plants since DEA cannot make a ranking for efficient DMUs. It gives only the efficient units.

\section{Case study}

In this study, efficiencies of thermal power plants public and private- in Turkey are compared. We consider power plants based on only natural gas and coal fired. For the efficiency analysis of thermal power plants, we generated two efficiency perspectives which are operational and investment based comparisons. The DEA model proposed for the operational performance evaluation of thermal power plants consists of six parameters. These parameters are based on expert opinions which are determined with respect to interviews made with firm representatives. The parameters include electricity production, operating cost, availability percentage, carbon monoxide (CO) production, thermal efficiency and environmental cost. Among these parameters, selected inputs are: carbon monoxide production, operating cost and environmental cost. Outputs are: electricity production, thermal efficiency and availability percentage. These parameters are selected as outputs since increase in their levels are desired.

Carbon monoxide production is the annual $\mathrm{CO}$ emission of the plant. The parameter is a significant indicator of the plants environmental impact and since decrease of the emission is a desired situation, the parameter is selected as input.

Operating cost is the total annual cost of the input fuel and labor cost used in the plant. It is selected as input since a decrease of operating cost is a desired change.

Environmental cost is the annual emission of environmentally hazardous particles. Since decrease in environmental cost is wanted, the parameter is selected as input.

Electricity production is the annual amount of electricity produced by the power plant and its unit is $\mathrm{kWh}$. The reason that this parameter is selected as output is that an increase in electricity production is a demanded change.

Thermal efficiency is the average annual efficiency of conversion to electric energy from the dissipated heat.
Availability percentage is the average annual percentage reflecting the time that the power plant is actually available for producing power. This parameter is an important indicator reflecting the reliability of the plant and taken as output since an increase in availability percentage is a positive change.

For the long term investment based efficiency, the DEA has four parameters which are investment cost, construction time, availability and power. These parameters are chosen to reflect the overall effectiveness of a electricity generating facility, during its full economic life. The first two are selected as inputs and the remaining are outputs.

Investment cost is the total capital used for the construction of the power plant for all the processes up to the start of operations. Since decrease in investment cost is wanted, the parameter is selected as input.

Construction time is the time passes from the start of the power plant construction to start of electricity production. It is selected as input since a decrease of construction time is a desired change.

Availability is the actual available time of the plant for electricity production in a 5 years period. This period is selected as 5 years rather than one year for reflecting long term reliability of the power plant. Availability is taken as output since an increase in availability is a positive change.

Power is parameter reflecting the electricity production capability of a power plant at a unit of time and its unit is MWh. Power is selected output since an increase in power is a positive change.

The data on the investigated power plants are combined under two sets: First is operational performance data set and the second is investment performance data set of thermal power plants. These two sets are displayed in Table 1. The efficiencies of the power plants are compared for different cases:

Case 1. Public and private power plants are analyzed for operational performances individually and compared.

Case 2. Public and private power plants are analyzed for investment performances individually and compared.

Case 3. All power plants are compared for operational and investment performances individualy.

Case 4. All power plants are compared for operational and investment performances together.

After their relative efficiencies are calculated by DEA model, the rankings of DMUs are determined. For making comparison of all power plants based on operational and investment performances together, it is seen that there is high correlation between variables $\mathrm{CO}$ (tone) and Production (MWh) as shown in Table 2 which is a handicap for DEA analysis. This situation directed us to remove 
$\mathrm{CO}$ (tone) variable from the analysis and also since variable Environmental cost (1000 \$) contains CO emission, it is unproblematic for our analysis. After this removal of input variable CO (tone), efficiencies of two DMUs change which are: Private 1 as 0.89 and Private 6 as 1.00 as indicated in Table 3.

According to overall efficiency results it can be seen that there are totally 5 inefficient DMUs. For making these inefficient DMUs efficient, we have used the reference set of each inefficient unit. In order to make an inefficient unit to be efficient, the gap between the inefficient unit and efficient units that are in its reference set must be closed. Target values for input values of inefficient units are calculated based on the corresponding input values of efficient units in the reference set. Table 4 presents reference sets for inefficient DMUs and their lambda values.

Input values of an inefficient unit which must be achieved to be efficient are calculated based on weighted average of its reference set input values as follows:

$$
n_{i k}=\sum_{j \in R_{i}} \lambda_{i j} o_{k j}
$$

where,

$R_{i}=$ reference set of DMU i

$n_{i k}=$ new value of parameter $k$ of inefficient DMU

$i$

$\lambda_{i j}=$ weight of reference unit $j \in R_{i}$

$o_{k j}=$ original value of parameter $k$ of reference unit $j \in R_{i}$

In order to clarify the calculations, the new value for investment cost of Public 2 is calculated as follows:

[(Private10 weight * Private10 investment cost) $+($ Private4 weight $*$ Private4 investment cost $)+$ (Public 7 weight * Public 7 investment cost)]

which yields:

$[(0.225 * \$ 9,988,601)+(0.038 * \$ 9,533,559)+$ $(1.037 * \$ 632,578,710)]=\$ 658,593,833$

So, in order to make inefficient Public2 as efficient, its investment cost should be increased from $\$ 625,057,330$ to $\$ 658,593,833$. Other target values for remaining inputs are calculated with the same manner. Target input values for inefficient units are given in Table 5. 


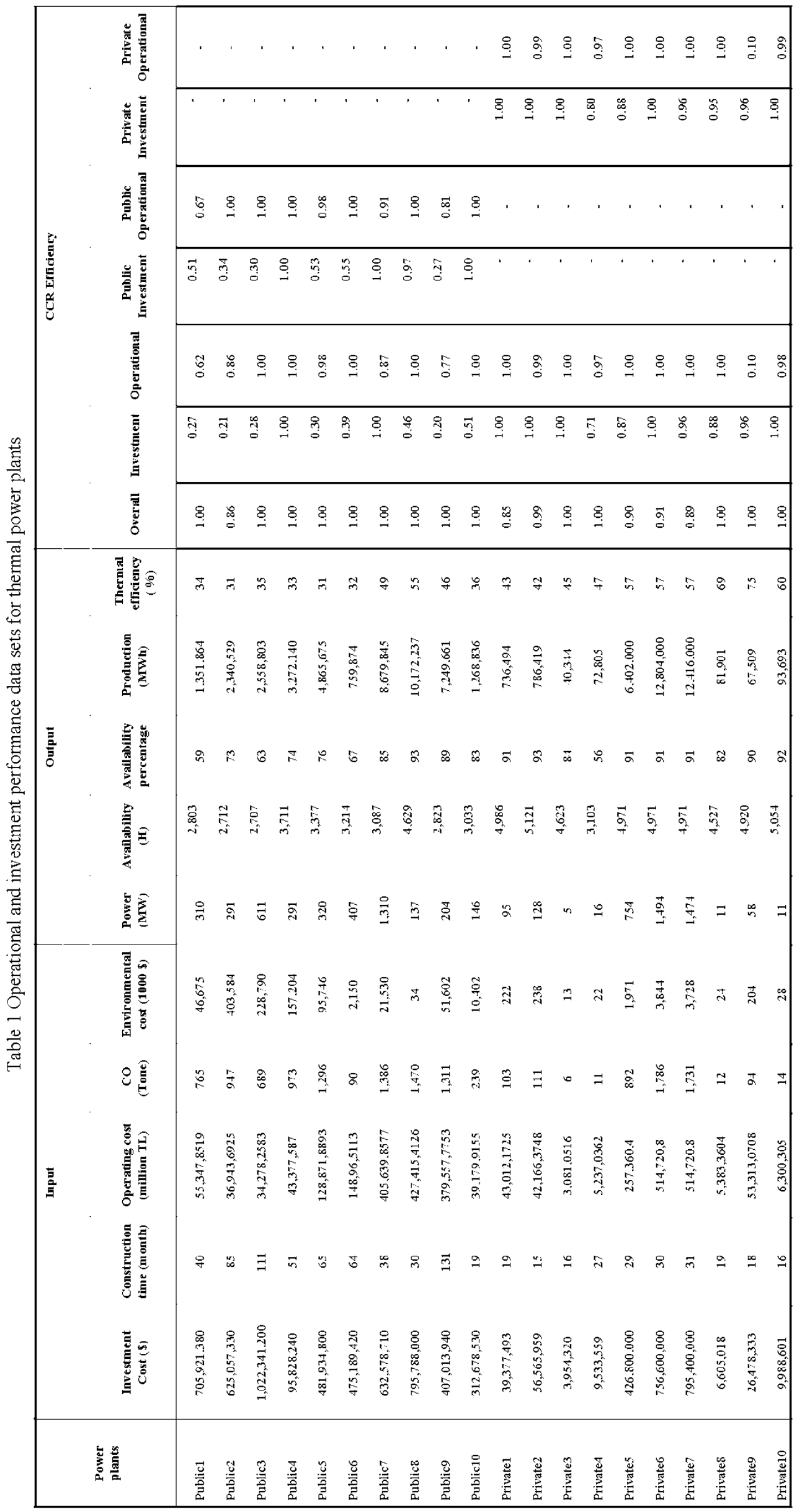

Co-published by Atlantis Press and Taylor \& Francis Copyright: the authors 


\begin{tabular}{|c|c|c|c|c|c|c|c|c|c|c|}
\hline 裏 & $\begin{array}{l}8 \\
0 \\
\\
\end{array}$ & $\frac{9}{9}$ & $\frac{9}{i}$ & $\tilde{z}$ & fo & $\tilde{\widetilde{d}}$ & 菅 & ְִ & $\frac{7}{i}$ & 8 \\
\hline 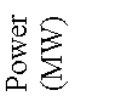 & $\stackrel{\circ}{\stackrel{0}{0}}$ & $\stackrel{0}{\stackrel{0}{0}}$ & $\stackrel{P}{?}$ & $\mid \begin{array}{c}\infty \\
0 \\
0\end{array}$ & i. & ণి & $\stackrel{E}{E}$ & 吕 & $\stackrel{8}{-}$ & $\stackrel{1}{9}$ \\
\hline 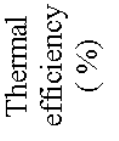 & : & $\frac{m}{9}$ & $\frac{\infty}{i}$ & $\hat{n}$ & $\frac{9}{0}$ & 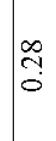 & $\begin{array}{l}8 \\
0 \\
i\end{array}$ & $\stackrel{8}{-}$ & $\because$ & $\stackrel{\overbrace{}}{2}$ \\
\hline 总咽 & $\stackrel{\infty}{\infty}$ & ஓे & $\stackrel{\substack{\infty \\
\infty \\
0}}{0}$ & $\stackrel{\tilde{y}}{\circ}$ & $\mid \begin{array}{l}\infty \\
0 \\
i \\
i\end{array}$ & $\overline{\tilde{\sigma}}$ & $\stackrel{8}{-}$ & $\begin{array}{l}8 \\
0 \\
0\end{array}$ & $\stackrel{F}{\circ}$ & is \\
\hline 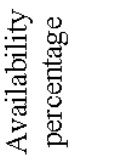 & $\hat{n}$ & 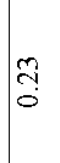 & $\frac{0}{1}$ & $\begin{array}{l}8 \\
0 \\
0 \\
\end{array}$ & $\stackrel{n}{i}$ & $\stackrel{8}{-}$ & $\overrightarrow{\tilde{m}}$ & $\mid \begin{array}{c}\infty \\
0 \\
0\end{array}$ & & $\tilde{0}$ \\
\hline 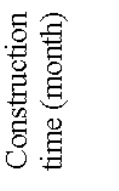 & 总 & 告 & $\stackrel{\circ}{\circ}$ & $\dot{0}$ & $\stackrel{8}{9}$ & $\frac{n}{9}$ & $\mid \begin{array}{l}\infty \\
0 \\
i \\
i\end{array}$ & $\frac{2}{0}$ & io & 年 \\
\hline 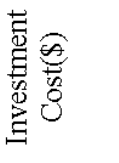 & 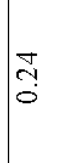 & 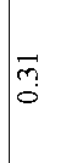 & ले & $\stackrel{8}{-}$ & $\stackrel{8}{\circ}$ & $\begin{array}{l}8 \\
0 \\
0 \\
i\end{array}$ & $\stackrel{\tilde{y}}{\tilde{\sigma}}$ & $\hat{n}$ & $\stackrel{\infty}{f}$ & đ̃ \\
\hline 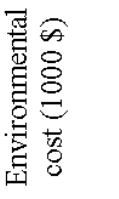 & $\stackrel{\circ}{\stackrel{0}{0}}$ & $\begin{array}{l}\infty \\
\infty \\
0 \\
0\end{array}$ & $\stackrel{8}{-}$ & ले. & $\stackrel{ }{\circ}$ & $\stackrel{\circ}{0}$ & 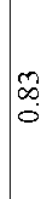 & $\frac{\infty}{\vec{c}}$ & $\stackrel{?}{0}$ & $\frac{2}{9}$ \\
\hline $8 \stackrel{\overparen{g}}{8}$ & $\hat{\alpha}$ & $\stackrel{8}{\stackrel{8}{-}}$ & $\begin{array}{c}\infty \\
\infty \\
0 \\
0\end{array}$ & $\overrightarrow{\bar{o}}$ & 售 & त̂ & ò & $\frac{m}{m}$ & $\stackrel{\circ}{\circ}$ & $\frac{9}{9}$ \\
\hline 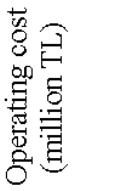 & $\underset{-}{\stackrel{8}{-}}$ & $\hat{\jmath}$ & $\frac{0}{2}$ & స్ & 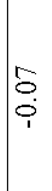 & & 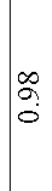 & $\stackrel{8}{0}$ & $\stackrel{\circ}{\stackrel{0}{0}}$ & $\begin{array}{l}8 \\
0 \\
0\end{array}$ \\
\hline & 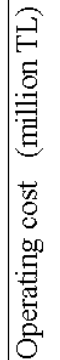 & 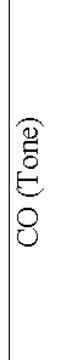 & 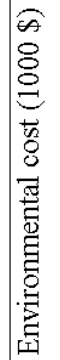 & 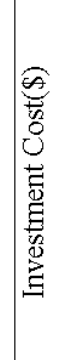 & 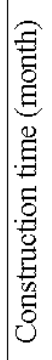 & 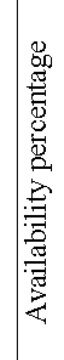 & 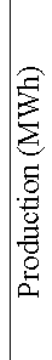 & 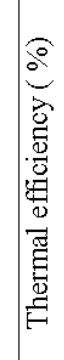 & 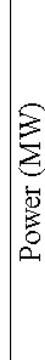 & 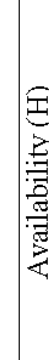 \\
\hline
\end{tabular}

Co-published by Atlantis Press and Taylor \& Francis Copyright: the authors 
Table 3. New Efficiency Scores

\begin{tabular}{lc}
\hline Power plant & Overall CCR Efficiency \\
\hline Public1 & 1.00 \\
Public2 & 0.86 \\
Public3 & 1.00 \\
Public4 & 1.00 \\
Public5 & 1.00 \\
Public6 & 1.00 \\
Public7 & 1.00 \\
Public8 & 1.00 \\
Public9 & 1.00 \\
Public10 & 1.00 \\
Private1 & 0.89 \\
Private2 & 0.99 \\
Private3 & 1.00 \\
Private4 & 1.00 \\
Private5 & 0.90 \\
Private6 & 1.00 \\
Private7 & 0.89 \\
Private8 & 1.00 \\
Private9 & 1.00 \\
Private10 & 1.00 \\
\hline
\end{tabular}

Table 4. Reference sets of Inefficient Power Plants

\begin{tabular}{|c|c|c|}
\hline Power Plant & Reference & da) \\
\hline \multirow[t]{3}{*}{ Public2 } & Private 10 & 0.225 \\
\hline & Private4 & 0.038 \\
\hline & Public7 & 1.037 \\
\hline \multirow[t]{2}{*}{ Private1 } & Private3 & 0.958 \\
\hline & Public5 & 0.401 \\
\hline \multirow[t]{2}{*}{ Private2 } & Private 10 & 1.295 \\
\hline & Public4 & 0.019 \\
\hline \multirow[t]{3}{*}{ Private5 } & Public7 & 0.226 \\
\hline & Private 10 & 0.338 \\
\hline & Public5 & 0.634 \\
\hline \multirow[t]{2}{*}{ Private7 } & Private 10 & 1.037 \\
\hline & Private4 & 0.225 \\
\hline
\end{tabular}

Table 5. Target Input Values for Inefficient Power Plants

\begin{tabular}{|c|c|c|}
\hline Power Plant & Input & Target Value \\
\hline \multirow[t]{5}{*}{ Public2 } & Investment Cost $(\$)$ & $658,593,832.74$ \\
\hline & $\begin{array}{l}\text { Construction time } \\
\text { (month) }\end{array}$ & 44.03 \\
\hline & $\begin{array}{l}\text { Operating cost } \\
\text { (million TL) }\end{array}$ & $4,209,892,966.73$ \\
\hline & $\mathrm{CO}$ (Tone) & 5.01 \\
\hline & $\begin{array}{l}\text { Environmental cost } \\
(1000 \$)\end{array}$ & 29.46 \\
\hline \multirow[t]{5}{*}{ Private1 } & Investment $\operatorname{Cost}(\$)$ & $197,044,093.40$ \\
\hline & $\begin{array}{l}\text { Construction time } \\
\text { (month) }\end{array}$ & 41.39 \\
\hline & $\begin{array}{l}\text { Operating cost } \\
\text { (million TL) }\end{array}$ & $546,292,750.40$ \\
\hline & $\mathrm{CO}$ (Tone) & 6.27 \\
\hline & $\begin{array}{l}\text { Environmental cost } \\
(1000 \$)\end{array}$ & $38,406.60$ \\
\hline \multirow[t]{5}{*}{ Private2 } & Investment Cost(\$) & $14,755,975.00$ \\
\hline & $\begin{array}{l}\text { Construction time } \\
\text { (month) }\end{array}$ & 21.69 \\
\hline & $\begin{array}{l}\text { Operating cost } \\
\text { (million TL) }\end{array}$ & $8,983,069.00$ \\
\hline & CO (Tone) & 36.62 \\
\hline & $\begin{array}{l}\text { Environmental cost } \\
(1000 \$)\end{array}$ & $3,023.14$ \\
\hline \multirow[t]{5}{*}{ Private5 } & Investment Cost(\$) & $451,885,598.80$ \\
\hline & $\begin{array}{l}\text { Construction time } \\
\text { (month) }\end{array}$ & 55.21 \\
\hline & $\begin{array}{l}\text { Operating cost } \\
\text { (million TL) }\end{array}$ & $1,735,923,360.00$ \\
\hline & $\mathrm{CO}$ (Tone) & 5.87 \\
\hline & $\begin{array}{l}\text { Environmental cost } \\
(1000 \$)\end{array}$ & $61,199.01$ \\
\hline \multirow[t]{5}{*}{ Private7 } & Investment $\operatorname{Cost}(\$)$ & $12,503,230.00$ \\
\hline & $\begin{array}{l}\text { Construction time } \\
\text { (month) }\end{array}$ & 22.67 \\
\hline & $\begin{array}{l}\text { Operating cost } \\
\text { (million TL) }\end{array}$ & $18,316,748.00$ \\
\hline & $\mathrm{CO}$ (Tone) & 16.99 \\
\hline & $\begin{array}{l}\text { Environmental cost } \\
(1000 \$)\end{array}$ & 33.99 \\
\hline
\end{tabular}

Co-published by Atlantis Press and Taylor \& Francis Copyright: the authors 
The efficiency measure obtained by DEA can be used for ranking DMUs, but this ranking cannot be applied to efficient units. Therefore we use goal programming which is one of the methods that can be used to rank the efficient units. While ranking efficient DMUs, some goals must be satisfied. The aspiration levels of these goals are given in Table 6 . These aspiration levels are determined by making interviews with firm representativeness and these levels correspond to goals of the firms. For example, average operating cost of the thermal plants cannot be greater than 194,229,000 million TL and operational availability must be at least $92 \%$, etc.

The general mathematical model of goal programming is as follows. Parameters of the model are;

$i=$ index of power plant

$j=$ criterion index $, j=1,2, \ldots, 6$ for operational criteria and $j=7,8, \ldots, J=10$ for investment related criteria, where; 1: operating cost 2: operational availability, 3: production, 4: environmental cost, 5: CO, 6: thermal efficiency, 7: investment cost, 8: construction time, 9: power, 10: availability

Table 6. Aspiration levels of goals

\begin{tabular}{|c|c|c|}
\hline Criteria name & $\begin{array}{l}\text { Goal values } \\
\text { (aspiration levels) }\end{array}$ & $\begin{array}{l}\text { Normalized } \\
\text { values }\end{array}$ \\
\hline Operating cost & $\begin{array}{l}194,229,000 \text { million } \\
\text { TL }\end{array}$ & 0.20 \\
\hline Oper availability & 0.92 & 0.25 \\
\hline Production & 7,601,700 MWh & 0.25 \\
\hline $\begin{array}{l}\text { Environmental } \\
\text { cost }\end{array}$ & $100,900 \quad(1000 \$)$ & 0.2 \\
\hline $\mathrm{CO}$ & $100,900 \quad(1000 \$)$ & 0.4 \\
\hline $\begin{array}{l}\text { Thermal } \\
\text { Efficiency }\end{array}$ & 0.43 & 0.2 \\
\hline Investment cost & $384,281,700 \$$ & 0.17 \\
\hline Construction time & 43 months & 0.18 \\
\hline Power & $833 \mathrm{MW}$ & 0.3 \\
\hline Availability & $833 \mathrm{MW}$ & 0.28 \\
\hline
\end{tabular}

$k=$ criteria that goal is set on, $k \in K$

$E=$ set of efficient DMUs (power plant) obtained from DEA model

$a_{i j}=$ the $j$ th value of public power plant $i$

$b_{i j}=$ the $j$ th value of private power plant $i$

$c_{j}=$ the right hand side value for the functional constraint related with criterion $j=5,6$

$g_{k}=$ the aspiration level for the goal constraint related with criterion $k$.

Decision variables of the model are;

$x_{i}=$ binary variable which is 1 , if the public power plant $i$ is selected ( $i=1,2, \ldots, 10$ ) which is 0 , otherwise

$y_{i}=$ binary variable which is 1 , if the private power plant $i$ is selected ( $i=1,2, \ldots, 10)$ which is 0 , otherwise

$d_{k}^{-}=$under achievement (negative deficiency) from objective $k$

$d_{k}^{+}=$over achievement (positive deficiency) from objective $k$

The mathematical model:

$\min \sum_{m \in K}\left(d_{m}^{-}+d_{m}^{+}\right)$

s.t.

$\sum_{i=1}^{10}\left(a_{i k} x_{i}+b_{i k} y_{i}\right)+d_{k}^{-}-d_{k}^{+}=g_{k}, \quad \forall k$

$\sum_{i=1}^{10}\left(a_{i 5} x_{i}+b_{i 5} y_{i}\right) \leq c_{5}$,

$\sum_{i=1}^{10}\left(a_{i 6} x_{i}+b_{i 6} y_{i}\right) \geq c_{6}$,

(4)

$\sum_{i \in E}\left(x_{i}+y_{i}\right)=1$ 


$$
\begin{aligned}
& x_{i}, y_{i} \in(0,1), \quad \forall i \\
& d_{k}^{-}, d_{k}^{+} \geq 0, \quad \forall k
\end{aligned}
$$

The objective function (1) aims to minimize the deviations from the goal constraints and the constraint (2) satisfies the goal constraints. Constraints (3) and (4) are the functional constraints which are written for criterion $\mathrm{CO}$ and thermal efficiency. Any goal related with these attributes isn't defined. Moreover, constraint (5) is the DEA efficiency constraint that provides ranking the efficient power plants which is the aim of this model.

In fact, this is the more general model (for case 4). When it is for only public or private power plants, or terms are discarded or when it is for operational or investment performances, then the criteria is taken only from 1 to 6 or 6 to 10 respectively.

When this model is solved, only one power plant is selected that satisfies these constraints. It means that it is the most efficient plant. Then the selected plant is discarded and the model is run for the remaining plants again. Then the second most efficient power plant is selected and goes on.

\subsection{Efficiency comparisons of public versus private power plants}

At first, comparisons are solely made between public and private power plants. In case 1 and 2 operational and investment performances are observed individually to decide on which plants are more efficient. In terms of investment performances the number of efficient private power plants is more than the number of efficient public plants. Because on average, investment cost of public sector plants is higher than that of the private sector plants (indicating the more expensive projects of the public sector). Furthermore, construction time of the public sector plants is also higher (this points to longer project completion times and longer lead times); moreover, public sector owns larger size plants. Another interesting point is that availability of the public sector plants is less than that of the private sector.

On the other hand, in terms of operational performances the number of efficient plants is similar in both of power plants. According to the data, average productions of the two subsets are similar (which actually enables a more reliable comparison regarding the other attributes). Availability values show the private sector to be more advantageous. An interesting point is environmental cost incurred by the public sector plants: The public plants have relatively higher environmental cost.

Then we observe all plants together in terms of operational and investment performances individually in case 3 . According to the operational efficiency results, again we see that the number of efficient public and private plants is similar. Therefore we construct the goal programming model and get the ranking of plants as seen in Table 7. Private power plants are more efficient than the public power plants. So, set of efficient power plants is determined by DEA methodology without making a ranking between them and their ranking is revealed by GP methodology.

In Table 8, investment efficient results are given. Similar results are obtained as in case 2 . Number of efficient public power plants is very low with respect to the private plants. Moreover, private power plants are ranked at the first orders again. Finally, we observe the efficiencies of all plants according to the all criteria involved operational and investment data together. But in this case, after we obtain the DEA results we construct a weighted goal programming.

We think together with the firm representatives that investment related goals are more important than the operational goals since huge investments are made in the construction of such plants and this affects the decision of constructing plants. Therefore we assign high weights to the investment related goals by talking with the experts of this subject.

Table 7. Ranking of power plants according to the operational efficiency

\begin{tabular}{ll}
\hline $\begin{array}{l}\text { Efficient plants } \\
\text { (DEA) }\end{array}$ & Ranked efficient plants (GP) \\
\hline Public3 & Private8 \\
Public4 & Private3 \\
Public6 & Private1 \\
Public8 & Public10 \\
Public10 & Private5 \\
Private1 & Private7 \\
Private3 & Private6 \\
Private5 & Public4 \\
Private6 & Public6 \\
Private7 & Public8 \\
Private8 & Public3 \\
\hline
\end{tabular}

When weights are included, the objective function of the model is changed as follows. We have eight goals and the last four are investment related. 
$\min \omega_{1}\left(d_{1}^{+}+d_{2}^{-}+d_{3}^{-}+d_{4}^{+}\right)+\omega_{2}\left(d_{5}^{+}+d_{6}^{+}+d_{7}^{-}+d_{8}^{-}\right)$ where $\omega_{1}$ denotes the weight of operational related goals and $\omega_{2}$ denotes the investment related goals and $\omega_{2}>\omega_{1}$.

Table 8. Ranking of power plants according to the investment efficiency

\begin{tabular}{ll}
\hline Efficient plants (DEA) & Ranked efficient plants (GP) \\
\hline Public4 & Private6 \\
Public7 & Public7 \\
Private1 & Private2 \\
Private2 & Private1 \\
Private3 & Private10 \\
Private6 & Public4 \\
Private10 & Private3
\end{tabular}

According to case 4 , the following results are obtained as given in Table 9. In this case, the number of efficient public power plants is higher than the private one but again the private plants are more efficient than the public plants except the public plant 7 according to ranking results. It is important to keep in mind that previous operational and investment based comparisons are performed on private and public power plants separately whereas comparison with respect to both operational and investment efficiencies are carried out on overall basis.

As a result, when we compare the efficiencies of public and private power plants, private plants are more efficient than the public plants. The result is not surprising since public power plants of Turkey are older than private ones which lead to older technology usage in public power plants. Furthermore, investment efficiency performances are higher for private plants and operational efficiency performances are similar for two types of plants.

\subsection{Efficiency comparisons of natural gas based versus coal based power plants}

For additional insight, the set of thermal power plants is decomposed according to input source (coal and natural gas). The comparison of these two subsets is made. The first five of public and private power plants are coal based and the remaining are natural gas based. According to Table 9involving operational and investment analysis together, coal plants seem to be at a clear disadvantage with respect to natural gas plants. Averagely, natural gas has higher efficiency scores relative to coal.
Furthermore, investment cost and construction time values of coal plants are higher than natural gas ones; availability, power, efficiency are also high for natural gas as seen in Figure 1. Moreover when we rank the efficient power plants, natural gas has the first orders.

Table 9. Ranking of power plants according to the operational and investment efficiency

\begin{tabular}{ll}
\hline Efficient plants (DEA) & Ranked efficient plants (GP) \\
\hline Public1 & Public7 \\
Public3 & Private9 \\
Public4 & Private10 \\
Public5 & Private3 \\
Public6 & Private8 \\
Public7 & Public8 \\
Public8 & Private4 \\
Public9 & Public9 \\
Public10 & Public5 \\
Private3 & Public4 \\
Private4 & Public10 \\
Private8 & Public6 \\
Private9 & Public1 \\
Private10 & Public3 \\
\hline
\end{tabular}

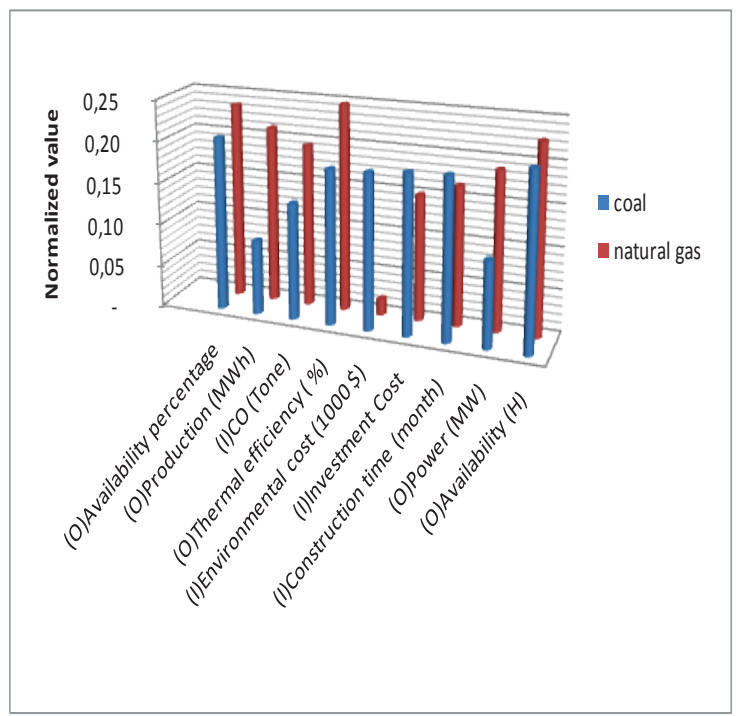

Fig. 1. Comparison of coal-based and natural gas-based power plants

Another comparison is made between public versus private coal based and natural gas based power plants as given in Figure 2 and Figure 3. An 
interesting point is that availability of public gas plants is lower than their privately owned counterparts. Higher investment cost of public sector comes from the larger size plants they operate; accordingly, construction time of public plants is also somewhat higher. This decomposition and analysis show that the main disadvantage of the public sector may be due to the coal based plants it owns.

Better management and adaptation of new technologies to these coal based plants can improve the situation. Environmental cost is expected to be higher for coal-based plants since $\mathrm{CO}$ level is higher more than the natural gas. This is proved when public plants are compared with private plants in Figure 2 and 3. Public power plants have also higher investment cost, lower availability and efficiency for both coal and natural gas based plants.

As a result, private coal-based and gas-based power plants have more advantageous than the public one because of these reasons.

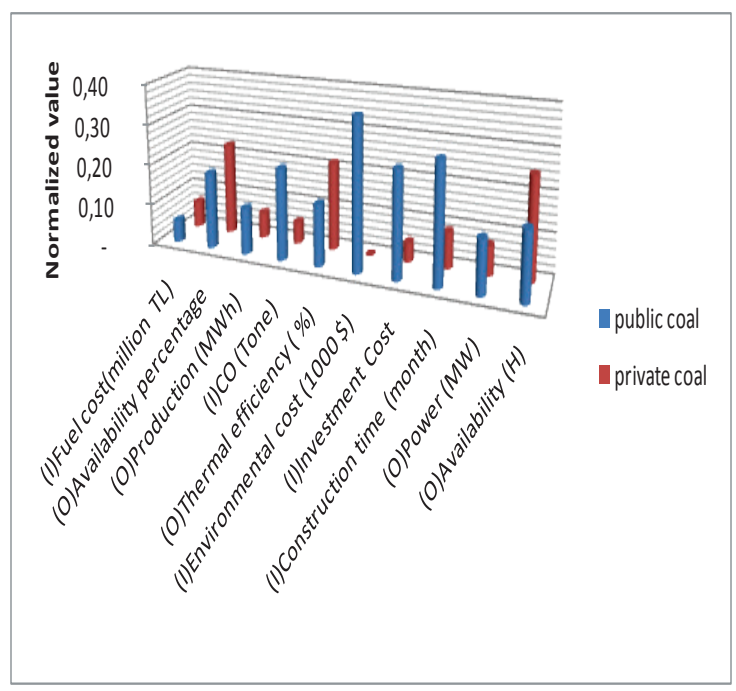

Fig. 2. Comparison of coal-based public and private power plants

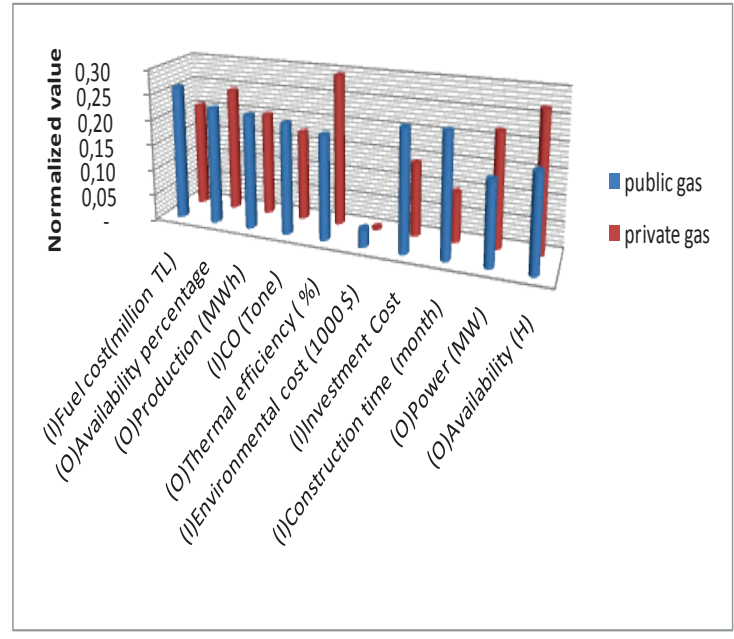

Fig. 3. Comparison of natural gas-based public and private power plants

\section{Conclusion}

Energy is a highly attractive sector that continues to grow by new investments with response to growing demand in Turkey. New utilities are being constructed by both public and private sector companies and this situation leads to the critical issue to determine on which energy source to invest. Thermal energy sources constitute the major part of energy supply and due to this reason, we focus on thermal energy power plants which are natural gas based and coal based ones. By using data envelopment analysis technique, efficiencies of thermal power plants are compared. After finding the most efficient ones, goal programming methodology is used to make a ranking between efficient power plants. Our study is an important research for providing guidance to energy sector actors that are eager to make investments in this sector.

For the study, 20 power plants are selected where half of them are privately owned and the remaining are public enterprises. All power plants belong to the group of thermal power plants since 10 of them are natural gas based and the other 10 are coal based plants. Operational and investment based criteria are the most important evaluation aspects for a power plant, due to this reason we compare investment and operational based efficiencies. For both public and privately owned power plants, investment and operational efficiencies are compared separately. Moreover, investment and also operational efficiency evaluation is done for the set of all power plants. Another evaluation is done for overall performance combining investment and operational efficiencies and all power plants are ranked according to their efficiencies. Finally, coal based and natural gas based power plants are compared with respect to their overall efficiencies. Also coal based private and coal based public plants are compared, in addition natural gas based private 
and natural gas based public plants are also compared.

Based on the results of the study, it is shown that based on their investment efficiencies, privately owned utilities are more efficient whereas they seem to be equal on operational performance. In comparison of energy sources, natural gas based power plants result with higher efficiency than coal based ones and natural gas power plants have more availability and efficiency values. Based on the comparison between natural gas based privately owned and public power plants, it is shown that public ones have less availability values and higher construction times. At the coal based power plant comparison, public power plants seem to have higher investment cost and lower efficiency values. Data envelopment analysis results give efficient and non-efficient power plants but it does not provide a ranking of efficient units. However it is very important to decide on the most efficient plant and have the plants ordered according to their efficiencies. This requirement is fulfilled with the help of goal programming technique. After data envelopment analysis yields the efficient power plants, we use goal programming by considering only these efficient plants and obtain a ranking between them. Goal programming approach is used for ranking efficient utilities with respect to their operational efficiencies, investment efficiencies and overall efficiencies. Based on the goal programming results, it is shown that private power plants are more efficient than public power plants. This study is valuable for giving insights not only on efficiencies of public and privately owned power plants but also efficiencies of coal based and natural gas based power plants. Data envelopment analysis and goal programming approaches are used for the evaluation. Future studies can be made by choosing different input and output parameters for the evaluation and also the study can be extended by taking other types of power plants into account like hydro and wind power plants.

\section{References}

1. K. Sarica and İ. Or, Efficiency Assesment of Turkish power plants using data envelopment analysis, Energy 32 (2005) 1484-1499.

2. A. Charnes, W. W. Cooper and E. Rhodes Measuring the efficiency of decision making units, European Journal of Operational Research 2 (1978) 429-443.

3. W. D. Cook and L. M. Seiford, Data Envelopment Analysis (DEA), Thirty Years On. European Journal of Operational Research 192 (2009) 1-17.

4. E. Thanassoulis, Setting achievement targets for school children, Education Economics 7(2) (1999) 101-119.

5. D.T. Barnum, S.M. Walton, K.L. Shields and G.T. Schumock, Measuring Hospital Efficiency with Data Envelopment Analysis: Nonsubstitutable vs. Substitutable Inputs and Outputs, Journal of Medical Systems 35 (2011) 393-1401

6. S. Mirmirani, Health Care Efficiency In Transition Economies: An Application Of Data Envelopment Analysis, International Business and Economics Research Journal (2008)

7. R. Corredoira, J.A. Chilingerian and J.R. Kimberly, Analyzing performance in addiction treatment: An application of data envelopment analysis to the state of Maryland system, Journal of Substance Abuse Treatment $\mathbf{4 1}$ (2011) 1-13.

8. S. Suzuki and P. Nijkamp, A stepwiseprojection data envelopment analysis for public transport operations in Japan, Letters in Spatial and Resource Sciences 4 (2011) 139-156

9. I. Fraser and D. Cordina , An application of data envelopment analysis to irrigated dairy farms in Northern Victoria, Australia, Agricultural Systems 59 (1999) 267 -282

10. N. Banaeian and M. Zangeneh, Study on energy efficiency in corn production of Iran, Energy, 36 (2011) 5394 - 5402.

11. S.M. Nassiri and S. Singh, Study On Energy Use Efficiency For Paddy Crop Using Data Envelopment Analysis (DEA) Technique, Applied Energy 86 (2009) 1320-1325.

12. S.H. Mousavi-Avval, S. Rafiee, A. Jafari and A. Mohammadi, Improving Energy Use Efficiency Of Canola Production Using Data Envelopment Analysis (DEA) Approach, Energy 36 (2011) 2765 -2772.

13. H.D. Sherman and G. Ladino, Managing bank productivity using data envelopment analysis (DEA), Interfaces 25(2) (1995) 60-73.

14. J. Johnes and L. Yu, Measuring The Research Performance Of Chinese Higher Education Institutions Using Data Envelopment Analysis, China Economic Review 19 (2008) 679-696

15. A. Kamakura Wagner, T. Ratchford Brian and A. Jagdis, Measuring market efficiency and welfare loss, J Consum Res (1988) 289- 302.

16. J. Parsons Leonard, Assessing salesforce performance with data envelopment analysis, TIMS Marketing Science Conference (1990).

17. S. Boles James, N. Donthu and L. Ritu, Salesperson evaluation using relative performance efficiency: the application of data envelopment analysis, $J$ Pers Sell Sales Management 15(3) (1995) 31-49.

18. Y. Lao and L. Liu, Performance evaluation of bus lines with data envelopment analysis and geographic information systems, Computers, Environment and Urban Systems 33 (2009) 247-255.

19. S. Onut and S. Soner, Analysis of energy use and efficiency in Turkish manufacturing sector SMEs, Energy Conversion and Management, 48 (2007) 384-394.

20. C. Martínez, Energy efficiency development in German and Colombian non-energy-intensive sectors: a non-parametric analysis, Energy Efficiency 4 (2011) 115-131.

21. W.O. Olatubi and D.E. Dismukes, A data envelopment analysis of the levels and 
determinants of coal-fired electric power generation performance, Utilities Policy 9 (2000) 47-59

22. J.R. Cristóbal, A multi criteria data envelopment analysis model to evaluate the efficiency of the Renewable Energy technologies, Renewable Energy 36 (2011) $2742-2746$.

23. W.S. Lee and K. Lee, Benchmarking the performance of building energy management using data envelopment analysis, Applied Thermal Engineering, 29 (2009) 3269-3273.

24. W. S. Lee, Benchmarking the energy efficiency of government buildings with data envelopment analysis, Energy and Buildings 40 (2008) 891895.

25. S.J. Sadjadi and H. Omrani, Data Envelopment Analysis With Uncertain Data: An Application For Iranian Electricity Distribution Companies, Energy Policy 36 (2008) 4247-4254.

26. M. Erturk and S. Türüt Aşık, Efficiency analysis of Turkish natural gas distribution companies by using data envelopment analysis method, Energy Policy 39(2011) 1426-1438.

27. A. Fallahi, R. Ebrahimi and S.F. Ghaderi, Measuring efficiency and productivity change in power electric generation management companies by using data envelopment analysis: A case study, Energy 26 (2011) 6398 -6405.

28. A. Sözen, I. Alp and C. Kilinc, Efficiency assessment of the hydro-power plants in Turkey by using Data Envelopment Analysis, Renewable Energy 46 (2012) 192 -202.

29. C.H. Liu, S.J. Lin and C. Lewis, Evaluation of thermal power plant operational performance in Taiwan by data envelopment analysis, Energy Policy 38 (2010) 1049-1058.

30. A. Charnes, W. W. Cooper, A.Y. Lewin and L.M. Seiford, Data Envelopment Analysis. Theory, Methodology and Applications (Kluwer Academic Publishers, Boston, 1997).

31. M. Tamiz, D. Jones and C. Romero, Goal programming for decision making: An overview of the current state-of-the-art, European Journal of Operational Research 111 (1998) 567-581.

32. C. Romero, Extended lexicographic goal programming: A unifying approach, Omega 29 (2001) 63-71

33. B. Golany, Y. Roll and D. Rybak, Measuring efficiency of power plants in Israel by data envelopment analysis, IEEE Trans. on Engineering Management 41 (3) (1994) 291301.

34. P. Chitkara, A data envelopment analysis approach to evaluation of operational inefficiencies in power generating units: a case study of Indian power plants, IEEE Transactions on Power System 14 (2) (1999) 419-425.

35. S.K. Behera, A.P Dash and J.A Farooquie, Performance evaluation and efficiency analysis of coal Fired Thermal Power Plants in India, Proceedings of the 2010 International Conference on Industrial Engineering and Operations Management (2010)
36. T. Sueyoshi and M. Goto, DEA approach for unified efficiency measurement: Assessment of Japanese fossil fuel power generation, Energy Economics 33 (2) (2011) 292-303. 